\title{
PEMODELAN EROSI SERTA PREDIKSI ANGKUTAN SEDIMEN DAN HARA PADA SUB DAS BUKIT TINDAWAN DAS KURANJI KOTA PADANG
}

\author{
Junaidi ${ }^{1}$, Yuzirwan Rasyid, Andri Ferdinand \\ ${ }^{1}$ Soil Survey and Classification Laboratory, Andalas U niversity Padang
}

\begin{abstract}
Land use change from agricultural land into non-agricultural land such as for industries, streets, and others has increased erosion impact, nutrient and sediment in a watershed. That process had caused land degradation in a watershed, therefore, land productivity will decrease and even will cause flood during rainy season and drought during dry season. In order to find out what will happen if land use change takes part, a software using BASIC language was arranged. This software is aimed to simulate erosion process easier. This software uses USLE and Snyder in predicting erosion. Additionally, this software is also able to predict sediment delivery.
\end{abstract}

Keywords: Software conservation, language BASIC.

\section{PENDAHULUAN}

Keberadaan sumber daya alam suatu negara sangat menentukan kelangsungan hidup penduduknya. Sumber daya alam, diantaranya tanah dan air telah tersedia dalam jumlah dan kegunaan yang cukup, namun perlu dilakukan tindakan pengelolaan yang tepat agar tetap lestari, seimbang dan berkesinambungan. Manusia merupakan komponen penting di dalam mengelola dan menggunakan sumber daya alam tersebut. Oleh sebab itu, kita harus memperhatikan kelestarian dan keseimbangannya agar tidak terjadi kerusakan.

Tanah dan air merupakan sumberdaya alam pada Daerah Aliran Sungai (DAS) yang peka terhadap kerusakan. Kerusakan tanah dapat berupa kehilangan unsur hara dari perakaran, terkumpulnya unsur hara atau senyawa yang merupakan racun bagi tanaman, serta tererosi. Kerusakan air dapat berupa menurunnya kualitas air yang disebabkan oleh kandungan sedimen yang bersumber dari kerusakan tanah dan erosi serta pencemaran oleh limbah yang di buang ke sungai.

Erosi tanah merupakan peristiwa penghancuran, pengikisan dan pengangkutan lapisan atas tanah oleh kekuatan pukulan butir hujan dan gesekan aliran. Faktor yang mempengaruhi erosi terutama iklim, tanah, topografi, vegetasi dan aktifitas manusia. Namun demikian tanpa campur tangan manusia erosi pun tetap berjalan secara alami tapi prosesnya berjalan dengan seimbang dengan pembentukan tanah. Dengan adanya gangguan manusia proses ini sering dipercepat sehingga kerusakan tanah yang kadang-kadang sampai pada tingkat yang mengkhawatirkan seperti penurunan produktifitas tanah, banjir yang terjadi setiap tahunnya, merosotnya debit sungai dimusim kemarau dan meningkatnya kandungan lumpur dimusim hujan. Hal ini merupakan petunjuk kerusakan sumberdaya alam di daerah aliran sungai. Pengelolaan yang baik bagi kedua sumber daya alam tersebut sangat dibutuhkan agar pemanfaatannya dapat dilaksanakan secara optimum dan lestari.

Aliran permukaan merupakan faktor utama penyebab kerusakan lahan dan daerah aliran sungai, baik melalui bahan-bahan yang terbawa oleh aliran permukaan maupun oleh aliran sungai. Bahan-bahan yang tersusupensi tersebut dapat dipakai sebagai indikator besarnya erosi yang terjadi di hulu. Kandungan sedimen tersuspensi pada daerah hilir dan kandungan unsur hara dari sedimen yang tersusupensi dapat pula 
menggambarkan banyaknya kehilangan unsur hara yang terjadi di hulu.

Kota Padang dengan luas $695 \mathrm{~km}^{2}$ dan penduduk yang berjumlah 750.000 jiwa (BPS, 2004), terletak pada dataran alluvial yang terbentuk oleh tiga aliran sungai utama, yaitu DAS Arau, DAS Kuranji dan DAS Air Dingin dengan daerah tangkapan hujan yang bersumber dari Gunung Bolak, Gunung Lantik dan Gunung Bongsu masing-masing seluas $172 \mathrm{~km}^{2}, 213 \mathrm{~km}^{2}$ dan $131 \mathrm{~km}^{2}$ (hasil interpretasi peta Topografi skala $1: 50.000)$.

DAS Kuranji merupakan salah satu DAS yang memiliki luas yang paling besar dibandingkan dengan DAS lain yang mengalir di kota Padang. DAS Kuranji memiliki aliran yang melewati kecamatan Pauh, kecamatan Kuranji dan kecamatan Nanggalo Kotamadya Padang. DAS Kuranji bermuara di Samudera Hindia, hulu sungai ini berada pada ketinggian \pm 1.858 meter dari permukaan laut (mdpl) dan hilirnya berada pada ketinggian $\pm 94,9$ mdpl. Sungai batang Kuranji mempunyai penggunaan lahan yang beraneka ragam seperti hutan belantara, semak belukar, lahan persawahan, tanaman holtikultura dan pemukiman (Hasil interpretasi peta topografi skala $1: 50.000$ ). DAS Kuranji beriklim tropis dengan temperatur maksimum rata-rata $18-30^{\circ} \mathrm{C}$ dan curah hujan rata-rata $3440 \mathrm{~mm} /$ tahun dengan kelerengan agak datar sampai curam. Berdasarka data diatas dapat kita perkirakan daerah ini rawan terhadap erosi yang akan berdapak menurunnya kualitas air dan tanah pada daerah ini (BMG Stasiun Klimatologi Gunung Nago. 2006).

Prediksi erosi serta kandungan sedimen dan hara yang terangkut di kawasan DAS dewasa ini sudah banyak dilakukan, prediksi ini diperlukan karena angkutan sedimen dan hara tersebut dapat berdampak terhadap lingkungan baik secara langsung maupun tidak langsung. Secara langsung sedimen dan hara yang terangkut tersebut dapat menyebabkan pencemaran lingkungan, sedangkan secara tidak langsung sedimen dapat menyebabkan sungai, waduk, danau dan saluran irigasi di daerah hilir menjadi dangkal sehingga daya gunanya berkurang. Untuk memprediksi hal ini, salah satu cara adalah dengan memodelkan kerusakan lahan. Faktor-faktor yang menjadi faktor determinan dimasukkan dalam perhitungan-perhitungan empiris sehingga dapat di simulasikan dengan menggunakan perangkat lunak seperti Microsoft Visual Basic (VB).

Visual Basic 6.0 (VB) adalah satu bahasa pemograman untuk membuat program aplikasi dalam lingkungan Microsoft Windows. Visual Basic yang digunakan biasanya dipakai oleh para penggunanya untuk dapat mengembangkan dan meracang suatu sistem analisis yang menggunakan bahasa program. Saat ini pemanfaatan sistem informasi terutama Visual Basic banyak diminati. Terutama mereka yang membutuhkan cara mudah untuk pengolahan data yang dijadikan sebagai acuan informasi yang dapat dimanfaatkan dan didedikasikan pada masyarakat.

\section{BAHAN DAN METODA}

Penelitian ini telah dilaksanakan pada bulan Agustus 2006 sampai November 2006 yang terdiri dari tiga tahap. Tahap pertama yaitu di lapangan untuk mengambil sampel air sungai dan tahap kedua di Laboratorium untuk analisis air, dan tahap ke-tiga di Studio komputer. Sampel air sungai diambil di bagian Sub DAS Bukit Tindawan Kecamatan Pauh Kota Padang, sedangkan analisis air dilakukan di Laboratorium Jurusan Tanah Fakultas Pertanian Universitas Andalas Padang dan pembuatan program di studio Survey Dan Pemetaan Jurusan Tanah Fakultas Pertanian Universitas Andalas. Bahan dan alat yang digunakan pada penelitian ini terdiri dari bahan dan alat yang digunakan di lapangan dan laboratorium. Bahan dan alat yang digunakan di lapangan adalah : botol plastik, kertas label, alat tulis, meteran kayu, stop wach, gabus, meteran dan Global Positioning System (GPS), sedangkan bahan dan alat yang digunakan di Laboratorium adalah : cawan, hot plate, eksikator, kolorimeter, Atomic Absortion Spetrophotometer (AAS), flamephotometer, labu ukur $1000 \mathrm{ml}, 500 \mathrm{ml}, 250 \mathrm{ml}$ dan 100 $\mathrm{ml}$, tabung pereaksi, pipet takar, gelas piala $1000 \mathrm{ml}$ dan $400 \mathrm{ml}$. Untuk alat yang 
digunakan pada studio komputer adalah satu (1) perangkat komputer. Penelitian ini telah dilaksanakan dengan menggunakan tahapan survey dan model anlisis data. Tahapan survey terdiri dari beberapa tahap, yaitu : (1) persiapan yang terdiri dari pengumpulan dan mempelajari data skunder serta survey pendahuluan, (2) survey utama dan pengambilan sampel air dan, (3) analisis air di laboratorium. Sedangkan tahapan model analisis data terdiri beberapa tahap yaitu : (1) pengolahan data, (2) perencanaan program dan (3) perencanaan diagram alir.

\section{Persiapan}

Pada tahap persiapan ini dilakukan pengumpulan data sekunder mengenai lokasi yang akan dilakukan penelitian. Data-data tersebut meliputi : peta dasar, peta kelas lereng, peta penggunaan lahan, dan peta satuan lahan.

Peta dasar yang digunakan pada penelitian ini adalah peta Topografi Jawatan Topografi Tentara Nasional Indonesia Angkatan Darat (JANTOP TNI AD) tahun 1984, dengan skala $1: 50.000$, helai 1223-II. Pada peta ini ditentukan batas sub das dengan menarik garis berdasarkan topografi yang membatasi Sub DAS Bukit Tindawan. Untuk lebih lengkapnya dapat dilihat pada Gambar 1A. „Peta lereng dibuat dengan mendeliniasi garis kontur yang mendeliniasi garis kontur yáng memiliki kerapatan yang sama, dan untuk persen kelerengan daerah yang telah dideliniasi tersebut menggunkan persamaan yang dikemukakan oleh Syarbaini (1987 cit, Hilmar 1991) yaitu :

$$
L=\frac{C l}{D} \times \frac{10000}{S}
$$

Dimana :
$\mathrm{L} \quad=$ Persen lereng $(\%)$
$\mathrm{CI}=$ Interval kontur $(\mathrm{m})$
$\mathrm{D}=$ Jarak antar kontur $(\mathrm{m})$
$\mathrm{S}=$ Skala Peta

Berdasarkan analisa dari persamaan tersebut didapatkan kelas lereng pada daerah Sub DAS Bukit Tindawan adalah seperti pada Gambar 1B.

Peta penggunaan lahan diperoleh dari survey lapangan dengan menggunakan GPS yang dikemukakan oleh Abidin, Jones dan Kahar (2002), yaitu dengan menentukan koordinat batas penggunaan lahan pada sub das bukit tindawan dan digambarakan pada peta dasar. Dari hasil survey tersebut di dapatkan jenis-jenis penggunaan lahan adalah seperti pada Gambar 2A. Peta satuan lahan diperoleh dengan menumpang tindihkan (overlay) peta lereng dengan peta penggunaan lahan. Dari hasil overlay tersebut didaptkan peta satuan lahan pada Sub DAS Bukit Tindawan adalah seperti pada Gambar 2B.

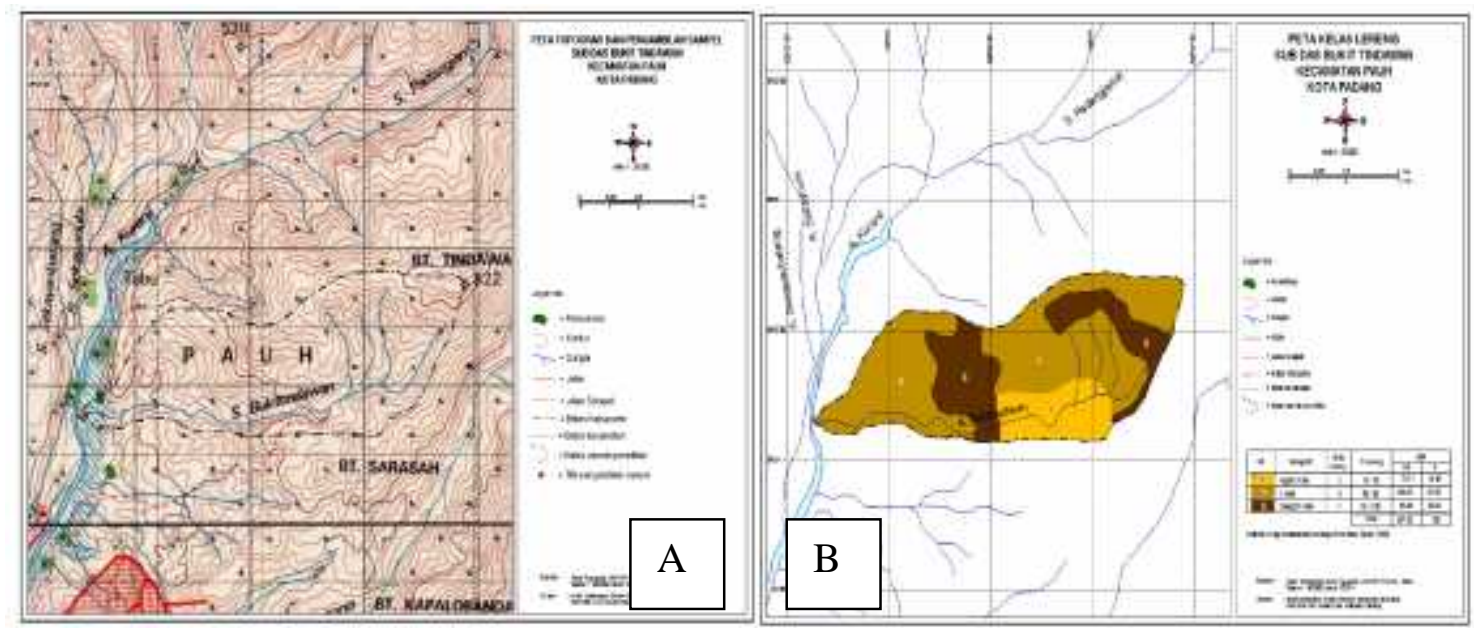

Gambar 1. Peta topografi (A) dan kelas lereng Sub DAS Bukit Tindawan Kecamatan Pauh Kota Padang 


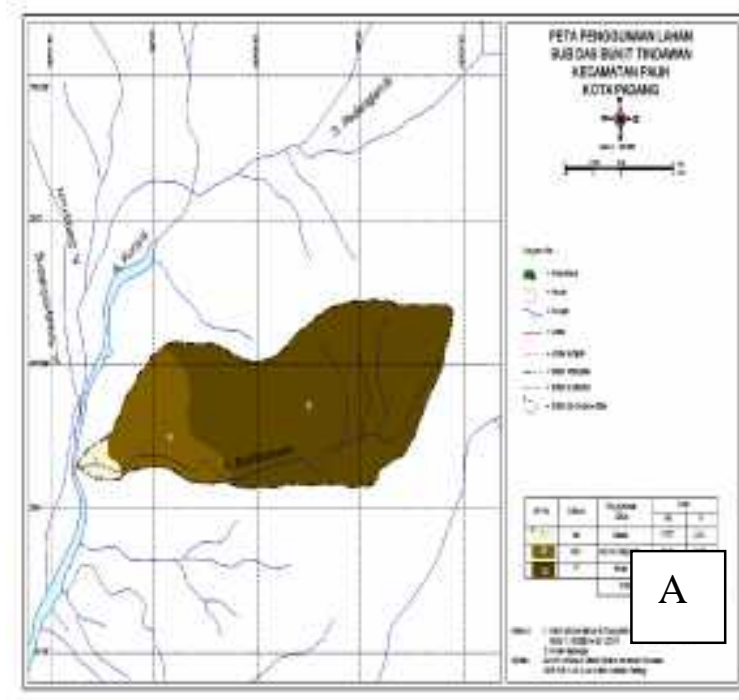

Gambar 2. Peta penggunaan lahan (A) dan Kecamatan Pauh Kota Padang

Survey pendahuluan

Survey pendahuluan dilakukan guna mengetahui keadaan lokasi penelitian di lapangan dan mencocokkan pada titik-titik pengamatan dipeta dengan titik-titik tempat pengamatan di lapangan agar mempermudah dalam survey utama dan pengambilan sampel air. Penentuan titk pengambilan sampel yaitu pada peta dasar yang disajikan pada Gambar 1A.

Survey Utama dan Penyampelan Air Pada survey utama dilakukan pengambilan sampel air di lapangan yaitu

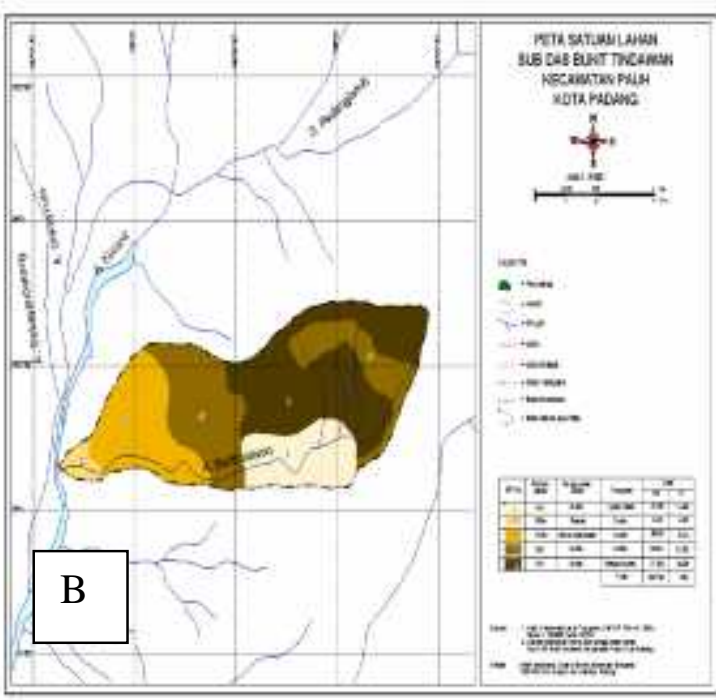

(B) sub das Bukit Tindawan pada titik yang telah ditentukan pada peta dasar. Pengambilan contoh air dilakukan saat kejadian hujan dan keadaan curah hujan $0 \mathrm{~mm}$. Pengambilan contoh air dilakukan pada 3 titik dari lebar sungai dengan jumlah pengambilan sebanyak 6 kali pada kejadian hujan dan 1 kali pada keadaan curah hujan 0 mm. Pada pengambilan contoh air juga dilakukan pengukuran debit sungai. Pengambilan sampel setelah hari hujan dikarenakan adanya lumpur dan kandungan hara disebabkan hujan yang membawa material dari hulu yang ditandai dengan keruhnya air dan besarnya debit air.

Tabel 3. Hubungan lebar sungai dengan banyak titik pengamatan pada pengukuran debit sungai ${ }^{1}$

\begin{tabular}{cc}
\hline Lebar sungai $(\mathrm{m})$ & Banyak titik \\
\hline $0-50$ & 3 \\
$50-100$ & 4 \\
$100-200$ & 5 \\
$200-400$ & 6 \\
$400-800$ & 7 \\
$800-1000$ & 8 \\
\hline
\end{tabular}

Soeharto (1970, cit Saidi 1985). 
Sedangkan pengambilan sampel air pada saat curah hujan $0 \mathrm{~mm}$ dimaksudkan untuk mengetahui kondisi debit angkutan sedimen dan hara dalam keadaan normal. Pengukuran debit sungai dilakukan dengan Analisis air di Laboratorium

Analisis air meliputi kandungan lumpur dan analisis hara. Penentuan kandungan lumpur dilakukan dengan menggunakan metoda evaporasi (penguapan). Sedangkan analisis hara digunakan cara yang dikemukakan oleh Suranta, Sudjadi dan Mulyani (1989) yang dipakai pada Pusat Penelitian Tanah Bogor. Unsur-unsur yang akan dianalisis meliputi (1) Penetapan Natrium (Na) dengan flamephotometer, (2) Penetapan Nitrat $\left(\mathrm{NO}_{3}\right)$ dengan kalorimeter, $\quad$ (3) Fosfat $(\mathrm{P})$ dengan kalorimeter, (4)Kalsium (Ca) dengan AAS, (5) Kalium (K) dengan flamephotometer dan, (6) Magnesium (Mg) dengan AAS.

Model analisis data

Pengolahan data

Hubungan atau korelasi antara debit sungai dengan kandungan lumpur tersuspensi serta kehilangan hara akibat aliran sungai dapat dinyatakan dalam suatu persamaan regresi sederhana. Sebelumnya ditentukan pasangan faktor yang saling berkorelasi tersebut :

- Antara curah hujan (X) dengan debit sungai (Y)

Antara debit sungai (X) dengan kandungan sedimen tersuspensi (Y)

- Sedimen tersuspensi (X) dengan kehilangan hara $(\mathrm{Y})$

Persamaan umum regresi linear sederhana yang digunakan :

$$
\mathrm{Y}=\mathrm{a}+\mathrm{bX}
$$

Dimana, $\mathrm{Y}=$ Variabel tidak bebas (curah hujan, sedimen tersuspensi serta kehilangan hara)

$\mathrm{a}=$ Intersepts

$\mathrm{b}=$ Bilangan yang menunjukkan beberapa perubahan nilai $\mathrm{Y}$ dengan dinaikkan 1 unit nilai $\mathrm{X}$ cara sederhana yaitu dengan metoda apung (Asdak, 1995). Untuk mengetahui hubungan antara lebar sungai dengan banyak titik penyampelan dapat dilihat pada Tabel 3.

$\mathrm{X}=$ Variabel bebas (curah hujan dan debit sungai)

Perencanaan program.

Pemodela erosi didasarkan persamaan yang dikemukakan oleh Wichmeir dan Smith (1978) yaitu dengan menggunakan persamaan USLE (Universal Soil Loss Equation):

$$
\mathrm{A}=\text { R.K.L.S.C.P }
$$

$$
\begin{array}{ll}
\text { Dimana : } & \mathrm{A}=\text { Erosi } \\
& \mathrm{R}=\text { Erosivitas } \\
\mathrm{K} & =\text { Erodibilitas } \\
\mathrm{L} & =\text { Panjang lereng } \\
\mathrm{S} & =\text { Kecuraman lereng } \\
\mathrm{C} & =\text { Vegetasi } \\
& \mathrm{P}=\text { tindakan konservasi }
\end{array}
$$

Pembuatan program prediksi angkutan sedimen dan hara didasarkan pada persamaan regresi yang telah didapatkan, yaitu dengan menghubungkan antara curah hujan dengan debit sungai. Untuk menentukan hubungan debit sungai dengan konsentrasi sedimen DAS atau "Sedimentdischarge rating curve" digunakan regresi kurva berpangkat yang dikemukakan oleh Asdak (1995).

Perancangan diagram alir

Diagram alir digunakan untuk menggambarkan tahapan penyelesaian masalah secara sederhana, terurai, rapi dan jelas serta setiap tahapan saling berkaitan, hal ini juga menggambarkan urutan logika dari prosedur pemecahan masalah dengan menggunakan lambang-lambang standar yang mewakili fungsi dan aliran sistem dalam memecahkan masalah berdasarkan input yang diperoleh sehingga dapat mudah di pahami. Untuk pemprosesan data dapat diurutkan seperti pada Gambar 3

Untuk pemodelan erosi digunakan database (data dasar) yaitu berupa : (1) permeabilitas tanah, (2) tekstur, (3) 
struktur, (4) kandungan bahan organik, (5) vegetasi, (6) tingkat konservasi ,(7) kelas lereng dan (8) panjang lereng. Data dasar tersebut akabn dihubungkan dengan persamaan USLE. Sedangkan untuk prediksi angkutan sedimen dan hara ditetapkan berdasarkan analisis laboratorium yang akan menghasilkan persamaan yang didapatkan dari literatur.

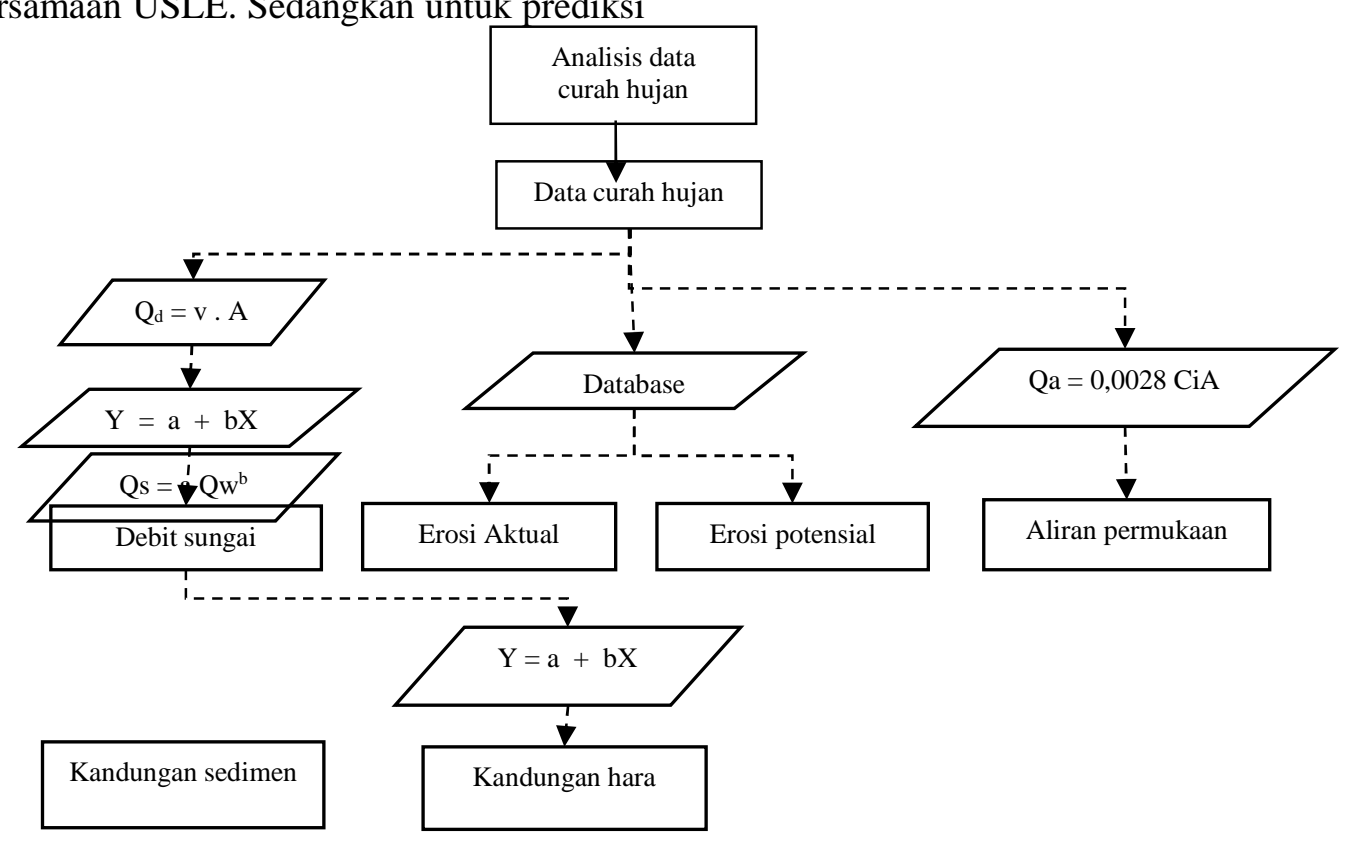

Gambar 3. Diagram alir pemodelan erosi serta prediksi angkutan sediemen dan hara

Penerapan logika pada prediksi ini adalah menghubungkan antara data curah hujan denagan aliran permukaan dengan menggunakan rumus :

$$
\mathrm{Qa}=0,0028 \mathrm{C} \text { i A }
$$

Dimana :

$\mathrm{Qa}=$ Air larian (debit puncak) $\left(\mathrm{m}^{3} / \mathrm{s}\right)$

$\mathrm{C}=$ Koefisien air larian

$\mathrm{i}=$ Intensitas hujan $(\mathrm{mm} / \mathrm{jam})$

$\mathrm{A}=$ Luas daerah DAS

Input yang digunakan adalah data curah hujan. Selanjutnya menghubungkan antara data curah hujan dengan debit sungai, pada peramalan debit sungai di gunakan rumus dasar debit sungai :

$$
\mathrm{Qd}=\mathrm{v} . \mathrm{A}
$$

Keterangan :

$\mathrm{Qd}=$ Debit aliran $\left(\mathrm{m}^{3} / \mathrm{s}\right)$

$\mathrm{v}=$ Kecepatan aliran $(\mathrm{m} / \mathrm{s})$

$\mathrm{A}=$ Luas penampang
Hubungan curah hujan dengan debit aliran dimasukkan ke dalam sebuah persamaan regresi :

$$
x=\frac{y-a}{b} .
$$

untuk menetukan hubungan debit sungai dengan angkutan sedimen di gunakan rumus:

$$
\mathrm{Qs}=\mathrm{a} \mathrm{Qw}^{\mathrm{b}}
$$

Keterangan: Qs $=$ Angkutan sedimen $\left(\mathrm{kg} / \mathrm{m}^{3}\right)$ $\mathrm{Qw}=$ Debit aliran $\left(\mathrm{m}^{3} / \mathrm{S}\right)$

$a$ dan $b=$ tetapan persamaan regresi

Nilai Qw berasal dari nilai $\mathrm{x}$ pada persamaan (1). Sedangkan untuk menghubungkan antara angkutan sedimen dengan angkutan hara di gunkan persamaan regresi :

$$
x=\frac{y-a}{b}
$$

a. Pembuatan program

Setelah mengetahui diagram aliran dan rumus atau persamaan yang di gunakan maka dirancanglah sebuah sistem untuk 
menyelesaikan permasalahan tersebut dengan berpedoman pada diagram alir yang telah dibuat. Sistem dirancang sedemikian rupa sehingga mampu memodelkan erosi

\section{HASIL DAN PEMBAHASAN}

Dari penelitian yang telah dilaksanakan maka didaptkan hasil sebuah software (perangkat lunak) yang mampu memprediksi erosi dan angkutan sedimen yang terjadi pada DAS maupun pada daerah pertanian.

\section{Representasi Diagram Alir}

Pembuatan diagram alir ini bertujuan memberikan gambaran terperinci dan terstruktur terhadap langkah membangun program, selain itu diagram alir membantu programer untuk membangun sistem. Ada beberapa hal yang perlu diperhatikan dalam pembuatan diagram alir ini yaitu basis data (database) dan relasi antara data. serta memprediksi aliran permukaan, sebit sungai serta kandungan sedimen dan hara yang terangkut dengan akurat.

Penjelasan logika realasi antara data yang di inputkan dengan basis data adalah faktor-faktor yang mempengaruhi dalam proses terjadinya erosi seperti vegetasi, tindakan konservasi, erosivitas, erodibilitas dan faktor lereng. Data-data ini dilaporkan dengan memanfaatkan Crystaol Report dan database tersimpan dalam Microsoft Acces.

Dapat dilihat pada diagram berikut (Gb.4) relasi database yang dimasukan dengan erosi yang terjadi. Sedangkan relasi antara curah hujan dengan angkutan sedimen dan hara yaitu dengan menggunakan persamaan regresi linear sederhana sehingga didapatkan persamaan yang konstan dan dapat dipakai sebagai ketetapan dalam relasi antara angkutan sedimen dan hara dengan curah hujan, untuk lebih jelasnya dapat dilihat pada diagram alir (Gb.5).

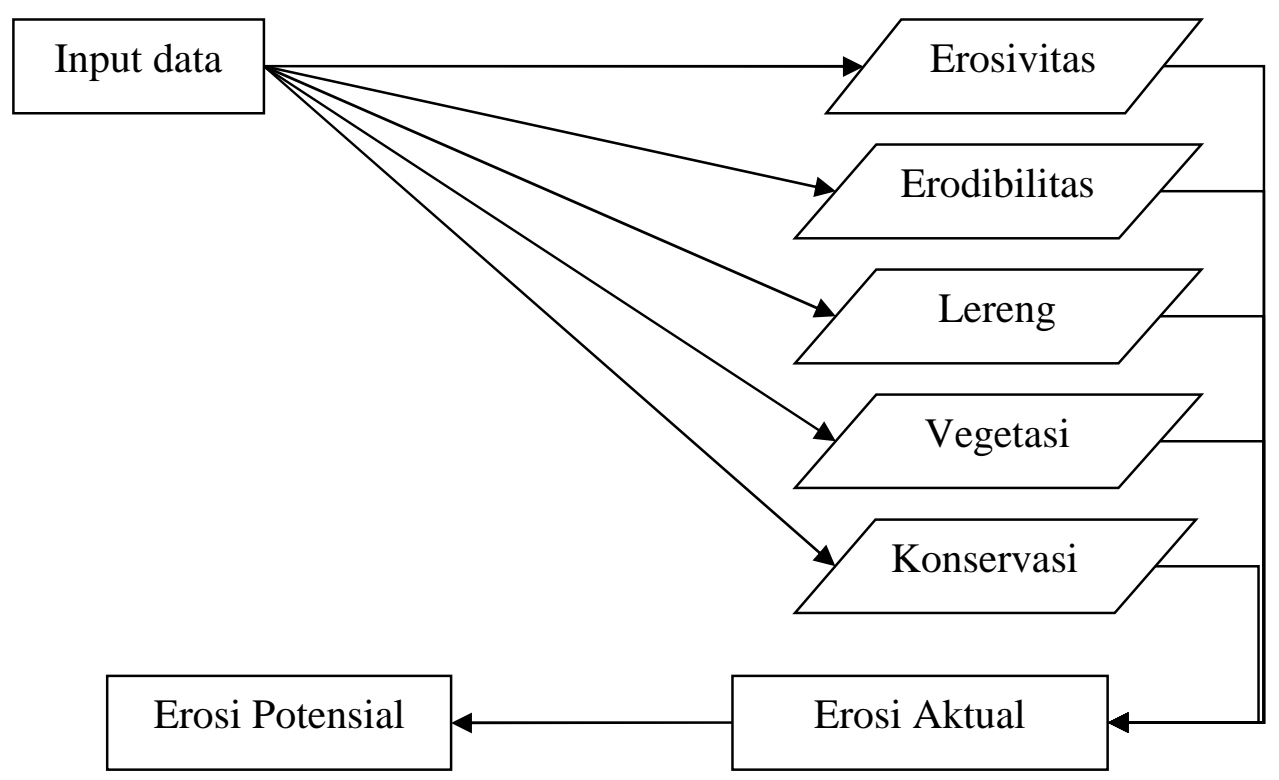

Gambar 4. Model input data 


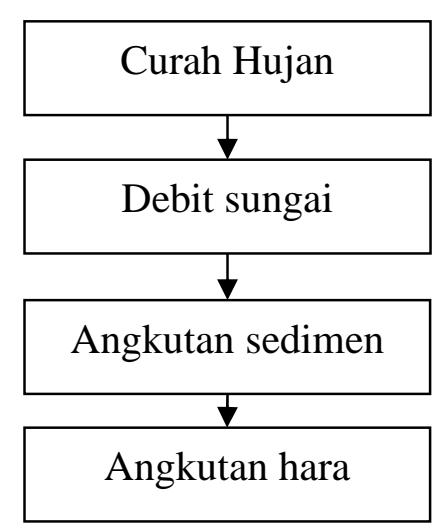

Gambar 5. Hubungan curah hujan dan angkutan hara

\section{Membangun Program Dan Validasi}

Program disusun berdasarakan deskripsi diagram alir yang telah dibuat, selanjutnya dibangun program komputer yang berisikan proses dan alur pengambilan keputusan yang tersruktur berdasarkan analisis diatas. Program ini akan dimulai dengan layar pembuka program, dimana fungsi layar ini sebagai introduksi program , memulai dan mengakhiri program seta penginputan data dan laporan. Untuk lebih jelasnya dapat dilihat pada Gambar 6.

Menu utama ini digunakan untuk memanggil modul-modul yang terintegrasi pada program ini antara lain menu memanggil prediksi erosi metoda USLE, metoda Snyder, prediksi aliran permukaan, prediksi angkutan sedimen dan hara, serta input data aliran permukaan, time consentration dan persamaan regresi untuk angkutan sedimen dan hara. Selanjutnya yaitu untuk memanggil modul laporan prediksi erosi, aliran permukaan dan angkutan sedimen dan hara.
Dengan adanya objek printah ini, diharapkan dapat memudahkan pengguna dalam memilih modul apa yang akan digunakan. Program akan dimulai dari menu utama dan akan diakhiri juga dengan menu ini. Pada menu ini terdapat prediksi erosi dengan metoda USLE, tampilan dari modul prediksi erosi metoda USLE dapat dilahat pada Gambar 6 berikut ini :

Modul atau form prediksi erosi metoda USLE terdiri dari beberapa jenis kotak kontrol (Control Box) diantaranya label, combo box, teks box dan command. Pada modul ini pengguna di hadapkan pada alur pengambilan keputusan dimana semua nilainya saling terkait satu sama lainnya dan akan mempengaruhi nilai dari erosi yang diprediksikan akan terjadi atau telah terjadi. Data-data yang masukan adalah nilai erosivitas, permeabilitas tanah, struktur tanah, tekstur tanah, kandungan bahan organik, panjang lerengan, persen lereng, vegetasi dan tindakan konservasi. Keluaran yang diharapkan dari form ini adalahn besarnay erosi yang terjadi.

Form berikutnya yang terdapat dalam perqangkat lunak ini adalah form

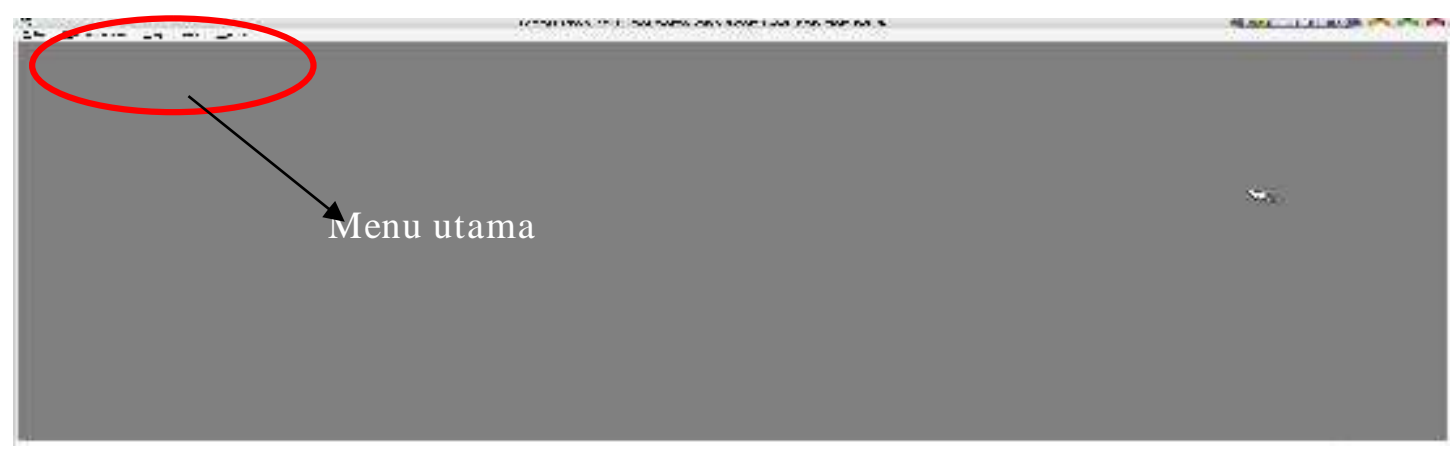

Gambar 6. Tampilan menu utama program. 


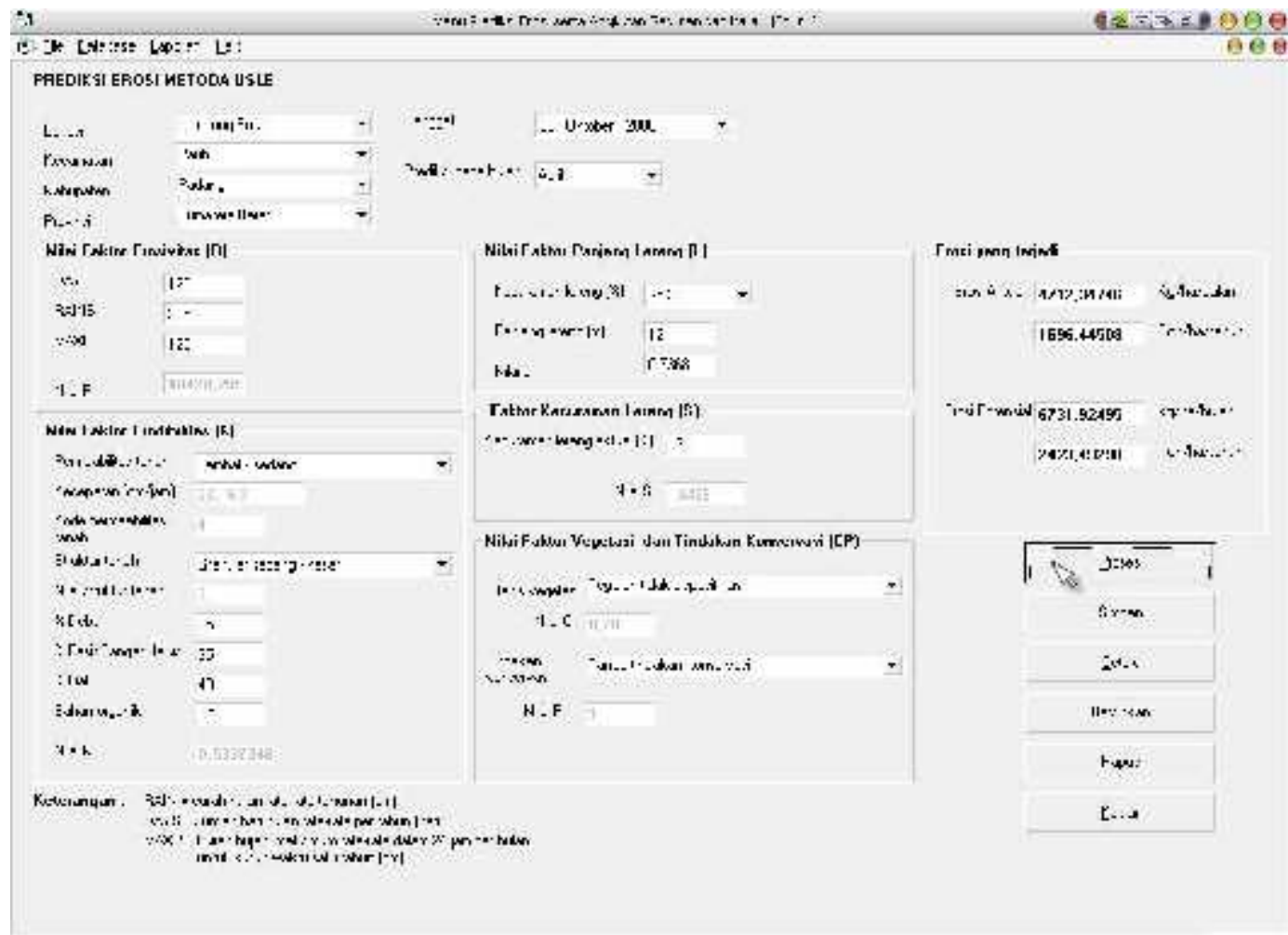

Gambar 7. Modul prediksi erosi dengan menggunakan metoda USLE.

prediksi erosi dengan menggunakan metoda Snyder. Dimana metoda Snyder bisanya diguanaka untuk lahan-lahan pertanian sedangkan metoda USLE biasanya digunakan untuk wilayah tangkapan air atau DAS (Asdak, 1995). Tampilan form prediksi erosi dengan metoda Snyder dapat dilihat pada Gambar 8.

Form ini memiliki control box yang sama dengan form prediksi erosi metoda USLE, hanya berbeda pada input data yang diperlukan dimana faktor vegetasi dan tindakan konservasi pada metoda USLE di ganti dengan faktor konservasi tanah dan sistem penanaman, keluaran yang diharapakan pada form ini adalah besarnya erosi yanag akan terjadi bila faktor-faktor yang mempengaruhinya diubah. Selanjutnya form yang terdapat pada perangkat lunak ini adalah prediksi aliran permukaan. Untuk memprediksi aliran permukaan pengguna harus meninputkan dulu data koefisien air larian pada menu input data. Selanjutnya dengan mengklik nama daerah maka data koefisien air larian akan muncul pada form prediksi aliran permukaan. Untuk tampilan form input data koefisien air larian disajikan pada Gambar 8.

Dalam menghitung koefisien air larian dengan menggunakan perangkat lunak ini perlu dikumpulkan data curah hujan ratarata dalam setahun dan luas DAS, karena data ini nantinya yanag akan mempengaruhi besarnya koefisien air pada DAS tersebut. Pengaruh dari curah huan dan luas DAS dapat dilihat pada persamaan berikut :

$$
C_{a}=\sum_{1}^{12} \frac{(d \times 86400 \times Q)}{(P / 1000)(A)}
$$

Dimana : $C_{a}=$ Koefisien air larian

$\mathrm{D}=$ Jumlah hari dalam 1 bulan

$\mathrm{Q}=$ Debit rata-rata bulanan

$$
\left(\mathrm{m}^{3} / \mathrm{dt}\right)
$$

$\mathrm{P}=$ Curah hujan setahun pada

DAS yang diteliti $(\mathrm{mm} / \mathrm{th})$

$\mathrm{A}=$ Luas DAS $\left(\mathrm{m}^{2}\right)$

Dari persamaan tersebut dapat dilihat bahwa semakin besar debit sungai yang terjadi maka semakin besar koefisien air larian yang terjadi (Asdak, 1995).

Hasil penghitungan pada form input data koefisien air larian akan dipanggil kembali pada form prediksi aliran permukaan. Indeks yang digunakan atau 


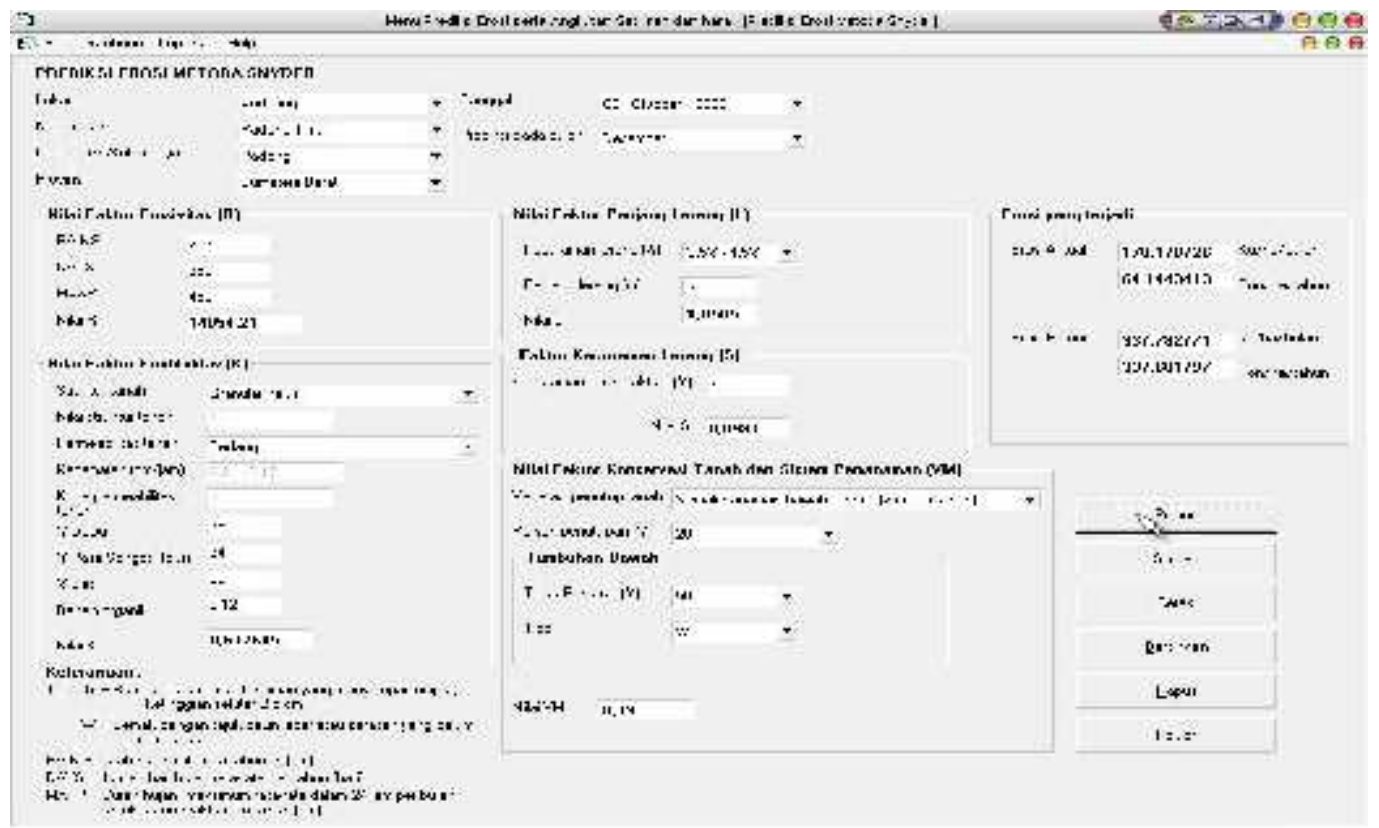

Gambar 8. Tampilan form prediksi erosi dengan metoda Snyder.

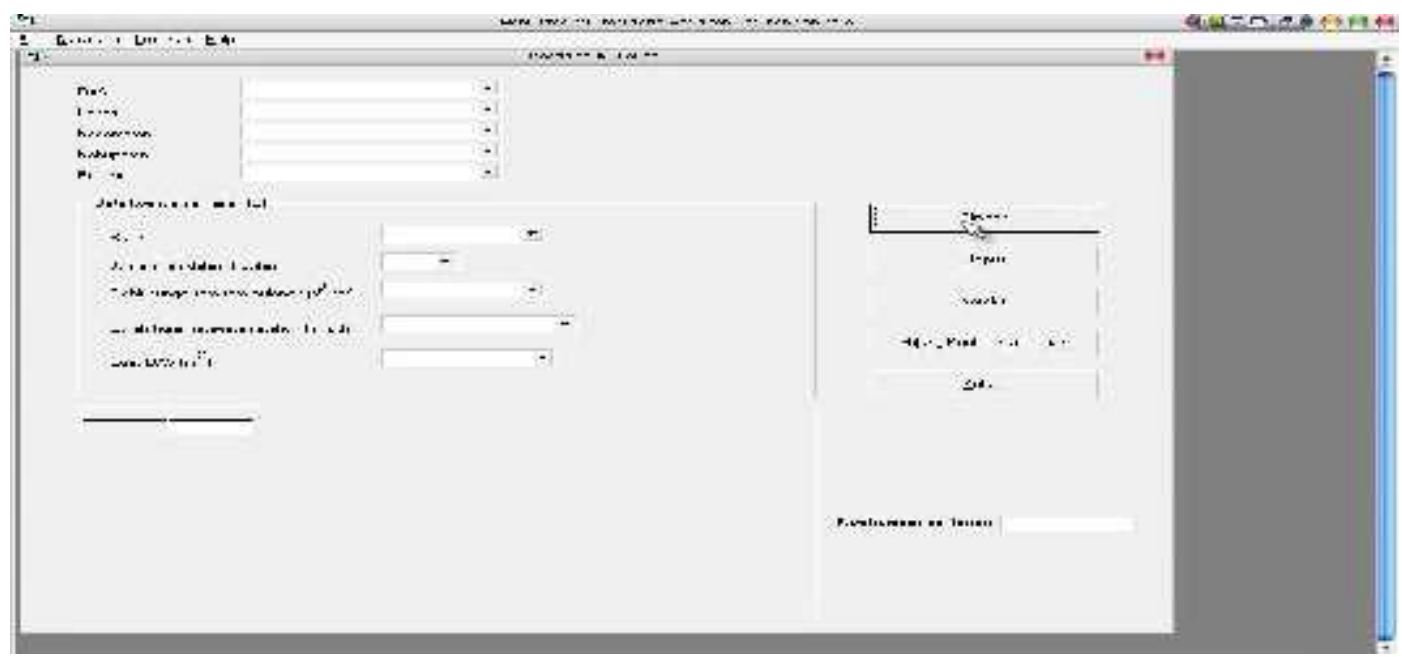

Gambar 9. Form input data koefisien air larian.

kata kunci yang digunakan untuk memanggil data koefisien aliran permukaan adalah lokasi. Tampilan form prediksi aliran permukaan dapat dilihat pada Gambar 9.

Dalam menghitung koefisien air larian dengan menggunakan perangkat lunak ini perlu dikumpulkan data curah hujan ratarata dalam setahun dan luas DAS, karena data ini nantinya yanag akan mempengaruhi besarnya koefisien air pada DAS tersebut. Pengaruh dari curah huan dan luas DAS dapat dilihat pada persamaan berikut :

$$
C_{a}=\sum_{1}^{12} \frac{(d \times 86400 \times Q)}{(P / 1000)(A)}
$$

Dimana : $\mathrm{C}_{\mathrm{a}}=$ Koefisien air larian

$$
\mathrm{D}=\text { Jumlah hari dalam } 1
$$

bulan

$\left(\mathrm{m}^{3} / \mathrm{dt}\right)$

$$
\text { Q = Debit rata-rata bulanan }
$$

$\mathrm{P}=$ Curah hujan rata-rata setahun pada DAS yang diteliti (mm/th)

$$
\mathrm{A}=\operatorname{Luas} \text { DAS }\left(\mathrm{m}^{2}\right)
$$

Dari persamaan tersebut dapat dilihat bahwa semakin besar debit sungai yang terjadi maka semakin besar koefisien air larian yang terjadi (Asdak, 1995). 
Hasil penghitungan pada form input data koefisien air larian akan dipanggil kembali pada form prediksi aliran permukaan. Indeks yang digunakan atau kata kunci yang digunakan untuk memanggil data koefisien aliran permukaan adalah lokasi. Tampilan form prediksi aliran permukaan dapat dilihat pada Gambar 9.

Untuk memprediksi besarnya aliran permukaan pada suatu kawasan DAS diperlukan data curah hujan selama 24 jam, panjang maksimum aliran DAS, beda tinggi antara bagian hulu dan hilir DAS, serta data intensitas hujan.

Form prediksi angkutan sedimen bila diaktifkan tidak akan berfungsi langsung jika data persamaan regresi pada basis data daerah DAS yang akan diprediksi tidak dimasukan terlebih dahulu. Persamaan regresi didapatkan dari analisis laboratorium sehingga basis data yang di inputkan diharapkan lebih akurat. Tampilan form input data angkurtan sedimen dan hara disajikan pada Gambar 10.

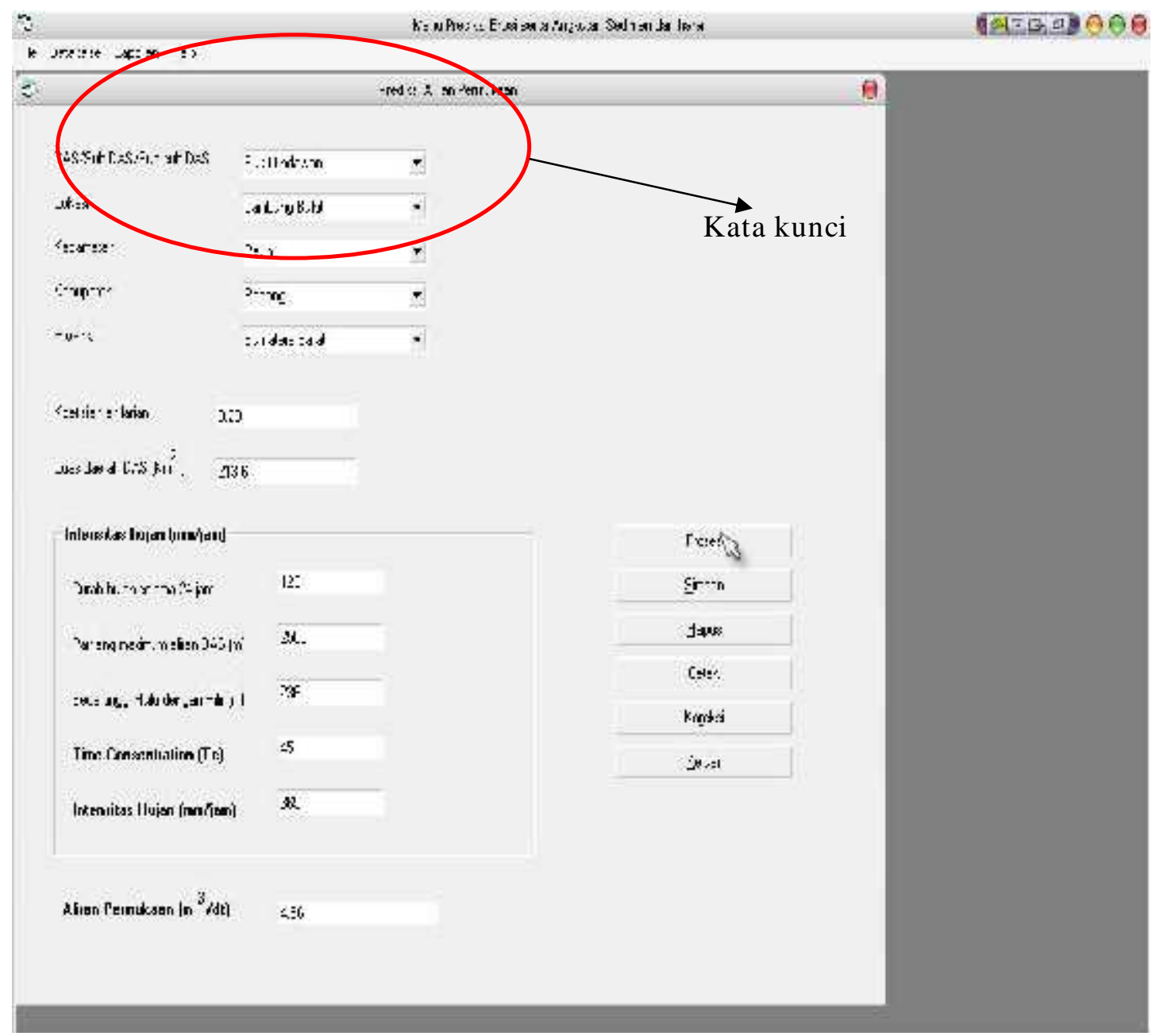

Gambar 10. Tampilan form prediksi aliran permukaan. 


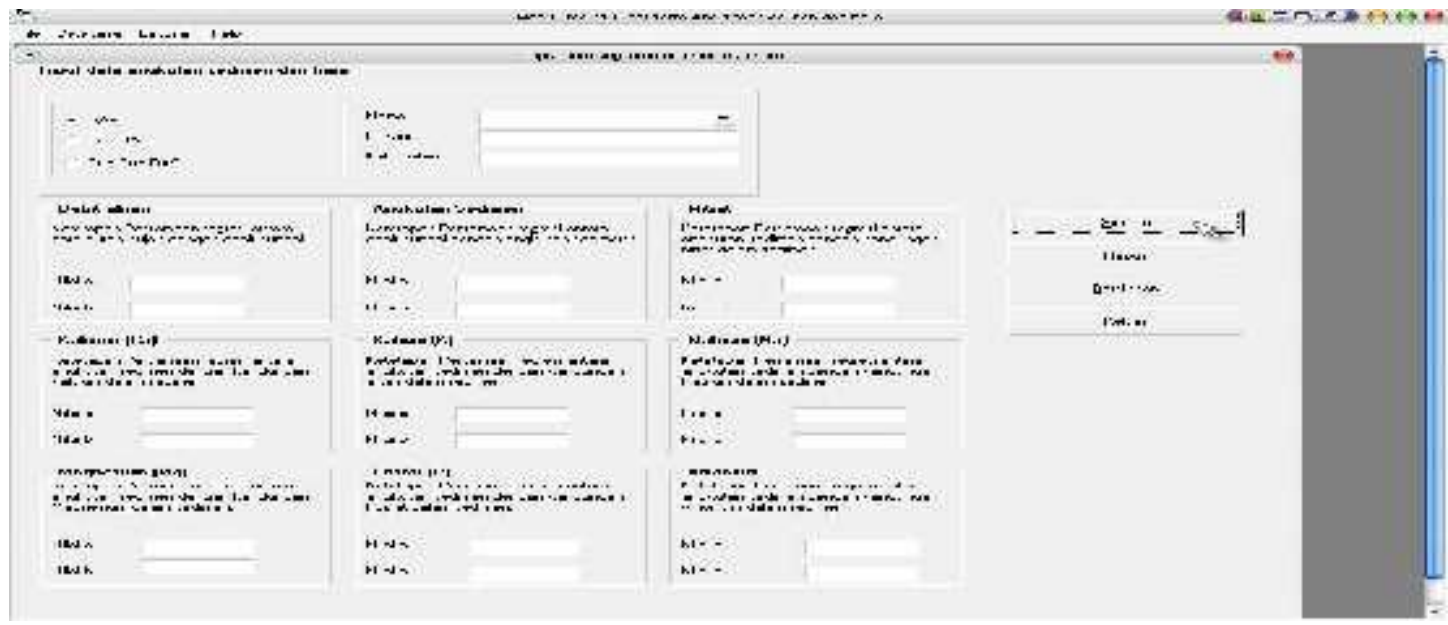

Gambar 11. Tampilan form input data angkutan sedimen dan hara.

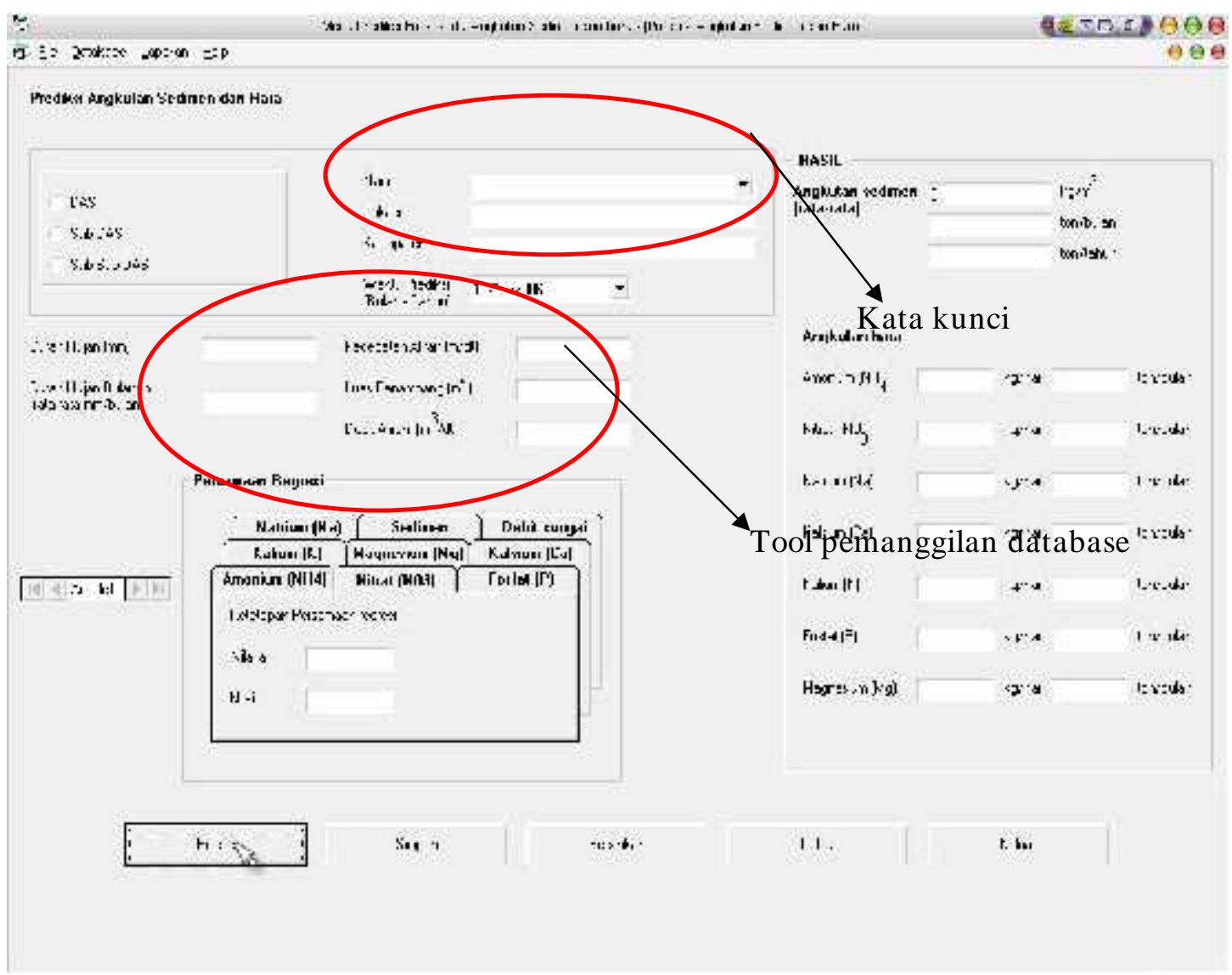

Gambar 12. Tampilan form prediksi angkutan sedimen dan hara.

Dari hasil input data pada form input data angkutan sedimen dan hara maka form prediksi angkutan sedimen dan hara bisa digunakan. Sama hal dengan form prediksi aliran permukaan pada form angkutan sedimen dan hara digunakan kata kunci lokasi, sehingga data yang telah disimpan dapat dipanggil sewaktu-waktu. Untuk memprediksi besarnya angkutan sedimen dan hara data yang diperlukan hanya data curah hujan baik itu curah hujan aktual maupun curah hujan harian, logika yang digunakan pada form ini adalah persamaan 
regresi yang telah diketahui hasilnya. Persamaannya adalah sebagai berikut :

$$
X=\frac{Y-a}{b}
$$

Dimana $: \mathrm{a}$ dan $\mathrm{b}=$ Tetapan persamaan regresi

$$
\begin{array}{ll}
\mathrm{X} & =\text { Debit atau sedimen } \\
\mathrm{Y} & =\text { Curah hujan }
\end{array}
$$

Tampilan form prediksi angkutan sedimen dan hara dapat dilihat pada Gambar 11.

\section{Report (Laporan)}

Perangkat lunak ini juga dilengkapi dengan fitur laporan atau report sehingga data yang telah diolah dapat dicetak langsung dengan batuan hardware Printer. Data-data yang telah diolah tersebut disimpan terlebih dahulu dengan bantuan perangkat lunak Microsoft Acces sebagai mesin penyimpan permanen dan Seagate Cristal Report sebagai media untuk mencetak dan penyimpan sementara dalam program ini. Perangkat lunak Microsoft Acces terintegrasi langsung dengan progeram ini sedangkan Seagate Cristal Report disertakan pada paket penginstalan program ini artinya perangkat lunak Seagate Cristal Report terpisah dengan program ini.

\section{KESIMPULAN DAN SARAN}

\section{Kesimpulan}

- Perangkat lunak yang dihasilkan dapat memprediksi besarnya erosi yang terjadi dengan memanfaatkan persamaan USLE untuk wilayah tangkapan air atau DAS dan persamaan Snyder untuk prediksi erosi pada lahan pertanian.

Perangkat lunak ini dapat memudahkan pengguna untuk mengetahui besarnya angkutan sedimen dan hara pada DAS, Sub DAS maupun Sub-sub DAS dengan cara pengoperasian yanag mudah.

Perangkat lunak ini juga mampu menghemat waktu untuk penghitungan prediksi erosi, prediksi angkutan sedimen dan hara serta prediksi aliran permukaan rata-rata sebesar 90 menit.
Saran

Perlu diadakan pengujian dan perbaikan basis data yang berkala pada perangkat lunak ini sehingga data yang dihasilkan tetap akurat

Perlu diadakan kajian yang lebih mendetail pada perangkat lunak ini sehingga input data dapat lebih disederhanakan sehingga data yang dimasukan bukan cuma angka namun lebih kepada faktor-faktor yang mempengaruhi prediksi tersebut.

\section{DAFTAR PUSTAKA}

Alam, A.J. M. 1999. M anajemen database dengan microsoft visual basic versi 6.0. PT Elex Media Komputindo. Jakarta.

Abidin, Z. H, A. Jones, J. Kahar. 2002. Survey dengan GPS. PT. Pradnya Paramita. Jakarta.

Arsyad, S. 1989. Pengawetan tanah dan air. Departemen ilmu-ilmu tanah. Institut Pertanian Bogor. Bogor.

Asdak, C. 1995. Hidrologi dan pengelolaan daerah aliran sungai. Gadjah mada university press. Yogyakarta.

Badan Meteorologi dan Geofisika. 2006. Curah hujan bulanan 1991 - 2005. Stasiun Klimatologi Gunung Nago. Padang.

Badan Pusat Statistik. 2005. Sumatera Barat dalam angka. Sumatera Barat.

Bermanakusumah, R. 1978. Erosi penyebab dan pengendaliannya. Fakultas Pertanian Universitas Padjadjaran. Bandung.

Hakim. N, M.Y. Nyakpa, A.M. Lubis, S.G. Nugroho, N.R. Saul, M.A. Diha, G.B. Hong, H.H. Bailey. 1986. Dasar-dasar ilmu tanah. Universitas Lampung. Lampung.

Harpiandi. 2003. Pemograman database dengan ADO menggunakan visual basic 6.0. PT Elex Media Komputindo. Jakarta.

Hilmar, F.D. 1991. Prediksi erosi dan penilaian besarnya sedimen daerah aliran sungai kuranji bagian hulu kotamadya Padang. Skripsi. Fakultas Pertanian Universitas Andalas. Padang. 
Isroi dan Ramadhan, A. 2004. Mikrosoft visual basic 6.0. PT Elex Media Komputindo. Jakarta.

Kang, B.T dan Lal, R. 1979. Nutrient losses in water run off from agriculture catcment in tropical geologi. Edited by Lal, R and Russel, E.W. Jhon Willey and Sons.

Purwowidodo. 1983. Tekhnologi mulsa. Dewa ruci press.

Robinson. A.R. 1979. Sediment yield as a function of upsteam erosion. SSA. Special publition. No 8 .

Saidi, A. 1995. Aliran permukaan, sedimentasi serta faktor-faktor yang mempengaruhinya serta dampaknya terhadap degradasi lahan di sub DAS sumani Solok Sumatera Barat. Disertasi. Pasca sarjana Universitas Padjadjaran. Bandung.

Suranta, W.I.M, M. Sudjadi, N.S. Mulyani. 1989. Penuntun analisa tanah dan air untuk klasifikasi tanah dan evaluasi Iahan. Pusat Penelitian Tanah, Bogor Syarief, E.S. 1985. Konservasi tanah dan air. Pustaka buana. Jakarta.

Seta. K. A. 1987. Konservasi sumber daya tanah dan air. Kalam mulia. Jakarta.

Utomo, W.H. 1994. Erosi dan konservasi tanah. Rajawali Press. Jakarta.

Utomo, W.H. 1995. Hubungan tanah air dan tanaman. IKIP Semarang Press. Semarang 